A N N A L E S Annales de Bretagne et des Pays de l'Ouest

\title{
L'Assèchement des marais en France au XVIIe siècle
}

\section{Michel Bochaca}

\section{(2) OpenEdition}

1 Journals

Édition électronique

URL : http://journals.openedition.org/abpo/2456

DOI : $10.4000 /$ abpo. 2456

ISBN : 978-2-7535-2129-2

ISSN : 2108-6443

Éditeur

Presses universitaires de Rennes

Édition imprimée

Date de publication : 30 juin 2012

Pagination : 205-207

ISBN : 978-2-7535-2127-8

ISSN : 0399-0826

\section{Référence électronique}

Michel Bochaca, "L'Assèchement des marais en France au XVIle siècle ", Annales de Bretagne et des Pays de l'Ouest [En ligne], 119-2 | 2012, mis en ligne le 30 juin 2012, consulté le 30 mars 2020. URL : http://journals.openedition.org/abpo/2456

Ce document a été généré automatiquement le 30 mars 2020.

(c) Presses universitaires de Rennes 


\title{
L'Assèchement des marais en France au XVIIe siècle
}

\author{
Michel Bochaca
}

\section{RÉFÉRENCE}

MORERA, Raphaël, L'Assèchement des marais en France au XVII ${ }^{e}$ siècle, Rennes, PUR, 2011, $265 \mathrm{p}$.

1 L'ouvrage constitue la version publiée d'une thèse d'université soutenue à Paris I en 2008. Le titre inscrit pleinement cette étude dans le champ de l'histoire des techniques, mais sa portée et son intérêt vont bien au-delà. Les rapports homme - nature sont appréhendés "par le haut » à partir de l'action de la monarchie et des élites qui lui servirent de relais durant le premier $\mathrm{XVII}^{\mathrm{e}}$ siècle, du règne de Henri IV à la minorité de Louis XIV. Cette perspective intéressante permet de réviser une historiographie ancienne, prompte à magnifier l'action royale comme celle de quelques grands commis de l'État et d'une poignée d'ingénieurs.

2 L'étude prend en compte la dessiccation de neuf marais français. Deux seulement sont intérieurs (Sacy-le-Grand, Sarliève) au regard des sept autres qui occupent une position littorale : deux en bordure de la Méditerranée (Capestan et Arles) et cinq sur la façade atlantique (Marais Vernier, Petit-Poitou, Tonnay-Charente, Lesparre-Médoc et Palu de Bordeaux). Difficiles à évaluer, les superficies bonifiées représentent entre 15000 à 25000 hectares, soit 15 à $25 \%$ des assèchements réalisés aux Pays-Bas à la même époque et qui, par bien des aspects, servirent de modèle.

3 Le chapitre I (Les marais, espaces convoités) brosse un panorama général des marais qui ont fait l'objet des entreprises de dessiccation. Décrits comme des espaces insalubres et répulsifs à partir du $\mathrm{XVI}^{\mathrm{e}}$ siècle, alors que, sous l'influence de des idées humanistes, des arguments «hygiénistes » commencent à s'imposer parmi les élites au pouvoir, les marais constituaient encore à la fin du Moyen Âge des «territoires utiles » qui rapportaient des revenus non négligeables à leurs propriétaires (poisson, roseaux, 
tourbe...) et procuraient des ressources complémentaires aux communautés qui possédaient des droits d'usage (cueillette, pacage du bétail...). Loin d'être des espaces naturels à l'abandon, il s'agissait de milieux partiellement aménagés par les hommes qui avaient essayé de domestiquer les eaux au moyen d'infrastructures hydrauliques (canaux, digues...) et avaient partiellement mis en culture les parties les mieux égouttées. À l'exemple du marais d'Arles, les guerres du Xvi siècle et surtout «l'esprit de clocher » des riverains empêchèrent une gestion concertée efficace.

Les chapitres II et III analysent la mise en place et le fonctionnement d'un système de dessiccation organisé depuis le sommet de l'État. Au prétexte qu'il en allait de l'enrichissement du royaume, Henri IV et Sully posèrent les bases d'un système que Richelieu consolida après eux. Quatre édits publiés entre 1599 et 1613 fournirent le cadre législatif qui conférait de larges pouvoirs aux dessiccateurs, tandis que la direction technique des opérations d'assèchement était confiée à ses débuts à un Brabançon disposant d'une solide expérience en la matière, Humphrey Bradley. Doté d'un monopole, ce dernier s'adjoignit des associés dont les premiers furent Conrad Gaussem à Bordeaux, le Sieur de Matignon en Médoc et la dame de Mortemart pour le marais de Tonnay-Charente. En 1605 naquit l'Association pour l'assèchement des lacs et marais de France. D'autres bailleurs de fonds s'intéressèrent à l'entreprise, tels les Comans, des Hollandais, fondateurs par ailleurs de la manufacture des Gobelins, et des commis de l'État (J. de Fourcy, A. Coiffier, L. Picot). À partir des années 1640, Richelieu puis Mazarin confièrent la direction de l'assèchement des marais d'Arles et du Petit Poitou à deux banquiers et commissionnaires de guerre, Jean Hoeufft et Barthélémy Hervart, relayés sur place par Octavio de Strada et Jan van Ens. Le renouvellement des acteurs au fil du temps traduit une évolution. À la différence de Sully, qui avait fait appel à ses soutiens politiques, Richelieu et Mazarin privilégièrent des banquiers fidèles, leurs réseaux économiques européens et leurs appuis aux Provinces-Unies. Euxmêmes s'impliquèrent plus directement que ne l'avait fait Sully, tandis que le montant des capitaux investis augmentait sensiblement. Mais ce changement de méthode ne traduit pas pour autant une rupture. Les assèchements sont activement poursuivis.

Les chapitres IV et $\mathrm{v}$ se centrent sur les aspects pratiques et techniques de la dessiccation. Dans le premier (chap. IV, Prendre possession de la terre), il apparaît que les oppositions furent plus fortes de la part des communautés qui possédaient des droits d'usage sur les marais que des seigneurs qui, une fois leurs droits garantis, collaborèrent assez volontiers. Le soutien inconditionnel de la monarchie, qui a mis au service des dessiccateurs les moyens de l'appareil de l'État, à commencer par la justice, a permis de vaincre les résistances, au point que la politique de bonification peut apparaitre en France comme une manifestation de l'absolutisme royal. Le dernier chapitre (Rentabilité et profit d'un modèle agricole) examine le «retour sur investissement » des dessèchements, après avoir présenté les grands traits techniques des aménagements hydrauliques réalisés. Les espaces agricoles ainsi gagnés sur les eaux furent majoritairement emblavés et leur production destinée à la commercialisation des grains. Les archives comptables conservées pour les Hoeufft permettent d'évaluer la rentabilité des opérations dans le marais du Petit-Poitou en 1670, 1685, 1686 et 1687, où la famille possédait une trentaine de métairies. En dépit d'oscillations annuelles sensibles (de 6000 à 20000 l. t.), le rapport des terres céréalières l'emportait largement sur les revenus tirés du bétail. L'exemple de la Palu de Bordeaux montre que les dessiccateurs ont également réalisé de confortables plus- 
values lors de la revente des terres (entre 2 et 24 fois la valeur d'acquisition) au cours de la première moitié du XVII ${ }^{e}$ siècle. L'entretien des aménagements hydrauliques constituait cependant un poste de dépense important et une source d'ennuis et de conflits.

6 À travers l'étude de l'assèchement des marais en France au cours du premier XVII siècle histoire des techniques, histoire économique et sociale et histoire politique se rejoignent et se mêlent avec bonheur. L'argumentation méthodiquement développée par Raphaël Morera est avantageusement servie par une quarantaine de figures (cartes, tableaux et graphiques). Au-delà de la vision d'ensemble proposée par l'auteur, des plongées au cœur de l'histoire propre de chacun des sept marais étudiés sont également possibles. En s'aidant de l'index des noms de lieux et de la table des figures chacun pourra retrouver ces fragments d'histoire locale qui constituent les pièces d'un puzzle plus important mais auquel Raphaël Morera a donné tout son sens historique à partir de la documentation disponible. 